\title{
Revisitando as três condições do ato propriamente virtuoso em Ética Nicomaqueia II 4
}

Priscilla Spinelli ptspinelli@gmail.com

Universidade Federal do Rio Grande do Sul (UFRGS), Porto Alegre, Brasil

resumo Este artigo pretende retomar a interpretação que pode ser chamada de tradicional das três condições do ato propriamente virtuoso expostas em EN II 4, i.e., o conhecimento, escolher deliberadamente 0 ato por ele mesmo e seguir-se de uma disposição firme e não hesitante. A atenção da análise será voltada à primeira e à terceira condição. Buscar-se-á mostrar que a condição do conhecimento pode ser compreendida como conhecimento das circunstâncias, do ato ele mesmo como virtuoso e das técnicas ou ofícios que podem ser por ele requeridos. Buscar-se-á igualmente justificar a introdução do termo 'disposição' na tradução apresentada, já que o termo grego 'hexis' não consta na passagem analisada. Um apontamento será feito, por fim, no sentido de oferecer uma justificativa mais ampla para a interpretação aqui defendida na medida em que a localiza como um posicionamento contrário à concepção intelectualista socrática.

palavras-chave ato virtuoso; agir virtuosamente; virtude moral; conhecimento; disposição; intelectualismo socrático

\section{Introdução}

Aristóteles responde, em Etíca Nicomaqueia (EN) II 4, a uma objeção à tese que a prática virtuosa é condição necessária para a aquisição da virtude moral. Tal tese é importante para Aristóteles porque responde ao menos em parte à questão da origem da virtude em nós ${ }^{2}$. As dificuldades que surgirem deverão ser não apenas assinaladas, mas também afastadas, o que será feito distinguindo a qualidade dos atos que engendram as disposições 


\section{4}

da dos atos que seguem das disposições, sendo que os últimos devem cumprir com três condições, caracterizando assim atos propriamente virtuosos. Além disso, Aristóteles indica aqui - como em outros momentos da $E E$ e da $E N$ - uma direção diversa da do intelectualismo socrático: o conhecimento, ainda que necessário para que ajamos bem e sejamos plenamente virtuosos - algo que só se esclarece completamente no livro VI, com a análise da phronesis -, não é, em primeiro lugar, o que nos caracteriza como virtuosos morais e não é de tipo filosófico, i.e., teórico.

Pretendo aqui fazer observações acerca das três condições dos atos propriamente virtuosos, em especial acerca da primeira, a saber, que o ato seja feito com conhecimento ou saber. Do modo como a interpreto nesse contexto, fica em aberto a possibilidade para uma futura especificação, o que acredito que será feito adiante, em EN III e VI. Em grande medida, pretendo mostrar a razoabilidade daquela que podemos chamar de interpretação tradicional especialmente dessa condição e mostrar também a razoabilidade de se compreender as três condições como um modo virtuoso de agir (que não está presente nos atos que engendram a virtude, mas apenas nos que se seguem dela). Pretendo, por fim, mostrar que é possível sustentar isso sem afirmar uma descontinuidade ou incongruência do texto da EN II. 4.

\section{I.}

A objeção apresentada em EN II. 4 consiste no seguinte: como é possível que agindo justamente eu me torne justo? Se estou agindo justamente, isso já não significa que sou justo, dado que, para agir assim, seria necessário que eu já dispusesse dessa qualidade? Não é isso o que ocorre nas artes, por exemplo, na gramática, quando então devemos dizer de alguém que escreve de acordo com as suas leis que ele é gramático?

Aristóteles observa que isso não é verdadeiro nem mesmo das artes: aquele que escreve corretamente pode ter feito isso por acaso ou sob a orientação de uma outra pessoa que sabe (cf. 1105a22-23). Para dizer de alguém que escreveu corretamente que ele é gramático, é preciso que ele tenha escrito corretamente "segundo a gramática que está nele" (cf. 1105a25). É preciso não apenas realizar certos atos, mas realizá-los 
pelas causas corretas, se quisermos atribuir-lhes uma qualidade - no caso, ser gramático.

Após assinalar que é possível escrever corretamente quer por acaso, quer sob a orientação de alguém, Aristóteles nota uma peculiaridade das artes, visto que o suposto adversário começa por comparar a atividade virtuosa com a artística. Nas artes, o objeto produzido é distinto e separado dos atos que o produzem, tendo certa qualidade independentemente dos atos que o produziram: para que digamos que uma palavra está escrita corretamente, basta observar a própria palavra, ou seja, o resultado do ato de escrever. Ainda que não tenha sido causada pelos conhecimentos gramaticais presentes no sujeito, quando a escrita é correta, ela é correta. A palavra 'jeito' tem nela mesma uma grafia correta, quer tenha sido assim escrita por mim por acaso, porque alguém "soprou"3 no meu ouvido ou porque eu sei (pouco importando, neste momento, o que deve ser compreendido por este saber) que esse é o modo correto de escrevê-la.

Por outro lado, nem todo ato que pode ser corretamente descrito como virtuoso é necessariamente virtuoso. Pois, como Aristóteles afirma ao longo da $E N$, diferentemente do que ocorre nas artes, o fim, "produto" ou "resultado" das ações não é diferente e separado delas, mas é essas próprias ações. Isso quer dizer que a característica externa de ser virtuoso não pode ser dissociada do modo como o agente realiza o ato. O que é importante, como Gauthier e Jolif observam, é que o ato virtuoso seja realizado de um certo modo para que seja corretamente descrito como um ato propriamente virtuoso (GAUTHIER \& JOLIF, 1959, 128).

Assim, além das características externas do ato, certas condições devem ser satisfeitas pela pessoa que o realiza. Aristóteles apresenta-as da seguinte maneira ${ }^{4}$ :

(...) os atos que são gerados pelas virtudes são praticados com justiça ou com temperança não quando apresentam certas características, mas quando o agente também age estando em um certo estado: primeiro, deve agir com conhecimento [eidos]; além disso, deve escolher por deliberação os atos, e escolhê-los por eles mesmos; terceiro, deve agir de acordo com seu caráter firme e inabalável ${ }^{5}$. Em relação à posse das artes, essas condições não são enumeradas, exceto o próprio conhecimento; com relação, porém, ao possuir as virtudes, o conhecimento [eidenai] tem pouco ou nenhum peso ${ }^{6}$; as outras condições contam não pouco, 
mas tudo, resultando justamente do praticar frequentemente atos justos e temperantes (EN II. 4. 1105a29-b4).

Como entender essas três condições e a relação entre elas? É possível compreender tais condições como 1) independentes, o agente satisfazendo-as uma a uma, o que implicaria a possibilidade, quando o agente não age de modo propriamente virtuoso, de cumprir apenas uma e qualquer uma delas, mas não as outras duas restantes. Por outro lado, 2) é possível ver que a primeira condição estabelece algo mais geral a ser cumprido, a segunda estabelecendo algo menos geral e a terceira algo ainda mais específico. Nesse caso, seria possível cumprir a primeira sem cumprir as demais, mas o cumprimento da segunda implicaria o cumprimento da primeira e o cumprimento da terceira implicaria o cumprimento das duas primeiras. Ainda, 3) elas podem ser vistas como uma mesma condição que se apresenta sob diferentes aspectos. Nesse caso, temos duas possibilidades: 3.1) tais aspectos não podem ser satisfeitos separadamente, pois estão em uma relação de dependência tal que a realização de um requer a satisfação do outro (na ordem em que foram apresentados); ou 3.2) tais aspectos podem ser satisfeitos separadamente, pois a relação entre eles não é de dependência, mas caracterizam o ato propriamente virtuoso apenas quando eles são satisfeitos conjuntamente pelo agente. Não tentarei impugnar as alternativas 1),2) e 3.1), pois isso requereria mais do que posso fazer aqui; limitar-me-ei no que segue a tentar mostrar a razoabilidade de 3.2).

Pode-se questionar também acerca do estatuto de cada uma dessas condições. Sobre a primeira, com a qual vou me ocupar mais, pode-se perguntar: a que conhecimento ou saber Aristóteles está se referindo? Por que ele o introduz como uma condição do ato virtuoso para logo depois dizer que, no que concerne à posse das virtudes, ele "tem pouco ou nenhum peso"? Quanto à segunda, pode-se perguntar se ela introduz ou não a escolha dos fins ao exigir a escolha do ato por ele mesmo, ou seja, como um fim, o que aparentemente é contrário à doutrina explícita do livro III, que restringe a deliberação e a escolha deliberada aos meios. E, em relação à terceira, pode-se perguntar: devemos ver aqui uma exigência do caráter já virtuoso do agente - e, devemos lembrar, a palavra hexis não aparece no texto que estou examinando - ou basta que ele se comporte de modo firme e inabalável no momento do ato para que digamos que seu ato foi propriamente virtuoso? 
Que opções temos para interpretar a primeira condição? Como Zingano explicitou, (ZINGANO, 2008, 112-113), ela pode ser entendida de quatro maneiras: (i) como o conhecimento que a ação em questão é virtuosa; (ii) como a maioria dos comentadores faz, como o conhecimento das circunstâncias em que a ação ocorre, (iii) como o conhecimento de regras morais sob as quais a ação em questão está subsumida ou (iv) os como os conhecimentos técnicos ou produtivos necessariamente envolvidos em toda ação virtuosa. À primeira vista, parece que se o conhecimento envolvido aqui fosse do tipo (i) ou (ii), ficaria dificil entender por que Aristóteles afirma poucas linhas depois que, em relação à posse das virtudes, ele "tem pouco ou nenhum peso". Ora, o conhecimento que o ato é virtuoso e o conhecimento das circunstâncias em que ele ocorre contam sim, e muito, para a posse das virtudes, pois é de atos virtuosos voluntários - não devidos à ignorância ou forçados - que as disposições para agir virtuosamente são engendradas e consolidadas, como ficará claro no livro III. Não pode ser, assim parece, o conhecimento das circunstâncias ou do ato como virtuoso o que é requerido e em seguida descartado.

A estratégia adotada por alguns comentadores para solucionar a dificuldade relativa a (i) e/ou (ii) é atribuir sentidos diferentes para as duas ocorrências quase imediatas de conhecimento (eidos, em 1105a31, e eidenai, em 1105b2). Stewart propôs essa solução:

Aristóteles usa eidenai em dois sentidos no presente contexto, sendo que de um deles ele afirma e do outro parece negar a necessidade para a moral.

Um homem deve saber que ele está realizando um ato, se o ato deve ter algum significado moral. Essa é uma condição indispensável (proton men ean eidos [1105a31]), como vimos acima. Mas, uma vez que essa condição foi satisfeita, é possível agir bem sem uma teoria da ação (to men eidenai [1105b2]), se os seus hábitos morais são bons (STEWART, 1892, 185).

Entretanto, isso parece apenas gerar mais um problema. Se entendermos a primeira ocorrência como conhecimento das circunstâncias e a segunda como conhecimento teórico ou filosófico sobre a ação, deveríamos admitir uma oscilação demasiada do pensamento de Aristóteles nessas poucas linhas. 
É possível, no entanto, encontrar uma interpretação para eidos e eidenai que, sendo única, seja compatível com o movimento do texto em questão e que não dependa da suposição de que Aristóteles teria inadvertidamente empregado um mesmo termo com acepções diversas em tão poucas linhas. Recusando que o conhecimento em questão possa ser (iii), i.e., o conhecimento de regras de conduta - pois isso apenas introduziria uma noção que, ao menos no contexto de EN II e III, parece não ter muita importância -, Zingano opta por (iv), o conhecimento técnico. Trata-se de um conhecimento tal e qual aquele das artes e oficios e que se pode também encontrar nos atos morais, pelo menos no que concerne à sua eficácia (ZINGANO, 2008, 113). Aquele que não sabe nada sobre equipamentos de guerra não poderá eficazmente defender a sua pátria; esta é uma condição necessária para agir corajosamente. No entanto, no que concerne à coragem, esse conhecimento tem pouco ou nenhum peso (ou "pouco ou nada conta", de acordo com a sua tradução): não é por saber como manejar certas armas e reconhecer qual ele deve utilizar em um determinado momento da batalha que dizemos de alguém que ele é corajoso, mas porque escolheu a ação - salvar a pátria, digamos - por ela mesma, agindo de modo firme e não hesitante ${ }^{7}$.

\section{III.}

Pretendo a seguir mostrar que é possível interpretar as duas ocorrências de 'conhecimento' como (i), (ii), (iii) e mesmo (iv) sem precisar, para isso, de um outro sentido - o de uma teoria moral - na segunda ocorrência. Pretendo mostrar também que a mesma explicação apresentada por Zingano para defender o sentido (iv) pode ser usada para sustentar os três primeiros. Para tanto, será preciso fazer uma distinção (a qual o próprio Zingano parece ter feito). De um lado, precisamos determinar para que é exigido o conhecimento (qualquer que ele seja, isso de fato não é especificado nesse momento); de outro, será preciso determinar para que ele é pouco ou nada importante, tem pouco ou nenhum peso.

Em vista disso, voltemos novamente ao texto de II. 4 e vejamos o caso da gramática: é possível escrever corretamente sem ser gramático? A resposta de Aristóteles é positiva e ele oferece as outras causas pelas quais 
alguém, mesmo sem ser gramático, poderia ter escrito corretamente: ele pode tê-lo feito por acaso ou sob a orientação de outra pessoa. Em ambos os casos, aquele que escreve, supondo que escreve corretamente, o faz não por causa do conhecimento de gramática que ele possui, mas porque arriscou um palpite feliz bem ou porque lhe "sopraram" a grafia correta da palavra. Quando não é realizada pelas causas próprias, a despeito da correção e da perfeição do produto, devemos negar que a escrita foi realizada de modo gramatical, negando, ao mesmo tempo, que é gramático aquele que assim escreveu. Sabendo gramática, aquele que escreveu corretamente por causa desse saber escreveu de modo gramatical. Além disso, simplesmente por possuir tal saber podemos dizer dele que ele é gramático.

O caso da ação virtuosa e da virtude é similar, sendo que o por causa de, no caso da virtude, implica cumprir as três condições apresentadas e não apenas a cláusula do conhecimento. Creio que elas não constituem três causas, mas uma só, a qual se expressa na ideia de um modo de agir. As três condições seriam então como que três aspectos que deveriam ser contemplados por aquele que age desse modo. Ora, aquele que age de modo virtuoso age sabendo o que faz. Isso significa que ele sabe o que conta como virtuoso a ser feito aqui e agora, reconhecendo o ato como tal, i.e., como virtuoso, e sabendo ele mesmo, na situação em que ele se encontra, como realizá-lo. Podemos ver, aí, a presença dos quatro sentidos de conhecimento distinguidos anteriormente (cf. páginas 4 e 5).

Entretanto, dizer que o agente precisa saber o que está fazendo quando age bem não é suficiente para descrever o estado em que ele se encontra quando age de modo propriamente virtuoso. Podemos saber o que é o virtuoso ou o melhor a ser feito e não fazê-lo, ou fazê-lo sem que esse saber seja de alguma forma o motivo para o que fazemos. É necessário, assim, que isto que o agente sabe ser o melhor a ser feito conte como razão ou motivação para a escolha do seu ato, i.e., que o ato seja realizado porque foi concebido como o melhor a ser feito. Por isso é preciso incluir aqui a segunda condição, i.e., que o agente escolha deliberadamente os atos por eles mesmos, ou seja, em razão de serem os corretos ou os melhores dadas as circunstâncias. ${ }^{8}$

Entretanto, tampouco descrevendo o bom ato desse modo afastamos completamente a possibilidade de o ato não ter sido realizado pela virtude. É preciso, ainda, que além de reconhecer o que conta como virtuoso e 
ter isso como razão para a escolha do ato o agente já tenha uma disposição para escolher e agir daquele modo, que ele tenha adquirido uma tendência para escolher realizar os atos virtuosos antes que os viciosos. Não pode ser o caso que o ato virtuoso seja um ato isolado na sua vida, mas sim algo que se siga do seu próprio caráter. Por isso, então, Aristóteles apresenta essa terceira condição: que o ato se siga da sua disposição já formada de caráter.

\section{IV.}

Gostaria agora de estabelecer algumas relações com as artes, tal como faz Aristóteles em EN II 4, explicando igualmente a necessidade da introdução do termo 'disposição' na terceira condição do ato propriamente virtuoso. É possível agir corretamente, i.e., cometer atos cujas características externas são consideradas virtuosas, sem ser virtuoso. Isso pode ocorrer pelas mesmas razões apresentadas para explicar a escrita correta cuja origem não é o conhecimento gramatical: podemos fazer isso por acaso ou sob a orientação de alguém. Podemos agir bem sem saber que estamos agindo bem, o que pode ser resultante do fato de ignorarmos uma ou mais circunstância(s) relevante(s) da ação. Por exemplo, podemos dar um remédio para combater a dor de cabeça de alguém e, de modo absolutamente acidental e não pretendido, ajudar a combater a sua dor de dente. Não sabíamos que o remédio poderia curar também a sua dor de dente, mas foi o que aconteceu. Por acaso, o resultado da nossa ação foi (mais) um bem para essa pessoa.

Algo um pouco diferente ocorre no caso da boa ação quando pedimos e seguimos conselhos, mas o princípio explicativo é o mesmo: agimos como agimos (desse modo, usando esses instrumentos, durante este período de tempo, etc.) porque alguém nos disse que isso era o melhor a fazer e não porque nós mesmos somos capazes de identificar aquilo que realiza a virtude aqui e agora. É assim, com efeito, que a educação moral se dá e que podemos, desde cedo, adquirir bons hábitos (ainda que não sejam, nesse momento, perfeitos ou completos), a saber, porque outros nos guiaram em uma tarefa que, nesse momento, ainda não éramos capazes de realizar por nós mesmos. E isso pode continuar assim nos casos em que consideramos dificeis. Querendo ajudar um amigo que está em 
dificuldades financeiras - esse é o fim -, podemos pedir conselhos a alguém justamente porque não sabemos como e/ou onde e/ou com quanto e/ou por quanto tempo - esses são os meios ou as coisas que realizam o fim - fazer isso. Assim, com a ajuda ou orientação de um outro, realizamos uma ação considerada virtuosa.

É possível, também, agir bem não por acaso nem sob a orientação de alguém, mas por uma outra razão que não a virtuosidade do ato. Por exemplo, podemos salvar alguém que está se afogando não para, simplesmente, salvá-lo, por pensar que a sua vida é algo valioso, mas porque queremos impressionar as pessoas que estão presentes ou porque pretendemos posteriormente ganhar uma recompensa. Nesse caso, escolhemos realizar uma ação reconhecida como virtuosa pelas razões erradas.

Por fim, é possível que eu mantenha firme a minha decisão e não hesite quanto à ação virtuosa a realizar: identifico o que, como, quando, com quem, etc. deve ser feito aqui e agora, escolho por ele mesmo, i.e., escolho fazer algo porque é nisto o que consiste o ato virtuoso a ser feito aqui e agora e não vacilo em relação a essa minha decisão. Este ato pode, no entanto, ser apenas esporádico ou continente, se, respectivamente, meus sentimentos não foram ainda educados ou se controlo alguns sentimento que não concordam perfeitamente com a minha decisão racional. Ora, esse dois casos só são possíveis se uma disposição para agir (ainda) não se instaurou no agente, aperfeiçoando como um todo os seus sentimentos e desejos. Por outro lado, a ação virtuosa deve poder ser descrita, também, como tendo sido causada pela disposição já virtuosa do agente: é preciso compreender a terceira condição como exigindo isso dele.

Entender a exigência de uma hexis como condição para a ação propriamente virtuosa, como a maioria dos tradutores e comentadores faz, parece perfeitamente compreensível e justificável: se um ato é propriamente virtuoso, ou seja, sob todos os aspectos e descrições possíveis, ele foi causado pela virtude, então aquele que escolhe agir assim, fazendo isso de modo firme e constante (ou não hesitante), não realiza o ato como uma ação pontual, podendo amanhã vir a agir de modo contrário, nem age dotado de um sentimento que o impulsiona no sentido contrário ao do ato, mas age como uma espécie de consequência de já ter agido assim muitas vezes. Age virtuosamente em sentido próprio apenas aquele que tem também como causa da sua ação uma disposição já formada. Aquele 
que cumpre a terceira condição apenas a título de manter firme a sua decisão no momento da ação, pode não possuir, ainda, o caráter estável; por isso, ele age, ainda, em conformidade com a virtude - que é também o caso do continente ou do aprendiz da virtude. É apenas quando a terceira condição é cumprida a título de disposição - incluindo as duas condições anteriores, certamente - que o agente pode ser dito agindo, completamente, por causa dela.

Aristóteles está apresentando as condições para que um ato seja realizado de modo virtuoso, como tenho insistido. Não pode ser o caso de ele exigir que apenas no momento da ação, o agente seja firme e não hesite em relação à sua resolução de agir virtuosamente. Se o agir de modo firme e não hesitante é algo que resulta de muitas vezes ter agido virtuosamente, como Aristóteles afirma em 1105b3, faz sentido afirmar que ele está se referindo ao caráter formado, a uma disposição. É isto o que resulta no agente após ter agido frequentemente de acordo com a virtude: uma disposição para escolher e agir e reagir emocionalmente antes assim que não assim. Em suma: não é o ato que deve ser firme e não hesitante (isso é, ainda, compatível com agir apenas conforme a virtude), mas o agente, sendo ele mesmo virtuoso.

\section{V.}

Aristóteles não se pronuncia, em EN II. 4, com relação à natureza do saber ou conhecimento cuja presença é condição para a ação virtuosa, mas argumentei que a interpretação da tradição pode ser mantida, a saber, vendo aí o conhecimento das circunstâncias ou do que nas circunstâncias consiste o agir virtuoso, reconhecendo-o como tal. Esse conhecimento pode também incluir, embora não se esgote nisso, o conhecimento técnico, tal como foi proposto por Zingano: se o que se deve fazer exige alguma habilidade técnica, é necessário tê-la também a fim de agir bem. Se isso envolve o conhecimento e/ou a aplicação de regras quaisquer, idem. Entretanto, afirma Aristóteles, enquanto condição para a posse das virtudes, o saber tem pouco ou nenhum peso. É preciso explicar essa exclusão e mostrar por que o conhecimento, compreendido desse modo - a saber, como qualquer um ou todos os quatro sentidos que explicitei 
anteriormente -, não requer a introdução de um outro sentido e, portanto, tampouco implica ruptura no entendimento da passagem que como um todo estamos considerando (1105a30-b4).

Creio que a solução para este problema consiste em observar que a identificação do que deve ser feito e de como deve ser feito (o que está necessariamente envolvido nos atos virtuosos) não é o que há de mais importante ou que mais pesa quando se trata de predicar a virtude de alguém, de dizer de alguém que ele possui virtude moral. Que o saber pese pouco ou nada para a posse da virtude não significa que ele pouco ou nada pese no seu processo de aquisição ou posse; ele pouco ou nada importa como critério para dizer se o processo chegou ou não à etapa final. Não é, em primeiro lugar, por saber identificar o que deve fazer, como e por que ele deve fazer isso, que um agente é virtuoso - embora ele precise saber isso, que é condição para agir virtuosamente, como Aristóteles afirma -; ele é virtuoso, em primeiro lugar, porque realiza os atos certos escolhendo-os por eles mesmos, os quais se seguem da sua disposição de caráter firme. Algumas pessoas são bastante inteligentes, perspicazes, sensatas, etc. nas suas avaliações e juízos de questões e situações práticas. No entanto, não é isso o que, em primeiro lugar, faz com que elas sejam moralmente virtuosas, boas: antes, isso faz delas inteligentes, perspicazes, sensatas, etc. em assuntos práticos.

Não se atribui virtude moral às pessoas pelo que elas sabem ou deixam de saber, pouco importando, na verdade, a natureza do conhecimento que está relacionado à ação: elas são reconhecidas como virtuosas pelas suas escolhas, pela constância e mesmo o prazer com os quais realizam os bons atos. Devemos dizer que algum conhecimento é necessário para agir bem, mesmo que não tenhamos ainda clareza acerca da sua natureza, e ele certamente está presente naquele que é virtuoso; não é esse conhecimento, no entanto, que responde, em primeiro lugar, pela virtude moral de alguém. É por isso que, em relação a ela, ele pouco ou nada pesa, importa pouco, nada ou quase nada.

\section{Conclusão}

Ao dar proeminência às condições mais estritamente práticas, negando, no que concerne à posse das virtudes, importância primeira ao conhecimento, 
Aristóteles não deixa de estar se dirigindo e respondendo a Sócrates. Saber o que deve ser feito, envolva isso o tipo de conhecimento que envolver - seja este filosófico, como pretendia Sócrates, ou estritamente prático, como Aristóteles vai mostrar no livro VI -, não é o que caracteriza, primeiramente, um caráter virtuoso. O prudente é também virtuoso, i.e., tem um bom caráter, mas não porque sabe o que deve ser feito, e sim porque escolhe fazer o que deve ser feito e reage emocionalmente às situações da maneira adequada. Negar que o conhecimento ou o saber tenha muita importância, nesse caso, é uma questão de ênfase: é preciso, em primeiro lugar, voltar-se às escolhas de um agente e aos seus sentimentos - i.e., ao seu caráter - para poder dizer de alguém que ele é ou não virtuoso moral.

Para responder, portanto, à objeção feita, Aristóteles se preocupou em estabelecer uma diferença entre os atos que são apenas conformes à virtude e atos que são feitos pela ou por causa da virtude. É isso, com efeito, o que deve ser compreendido para afastar o aparente círculo envolvido na tese segundo a qual é agindo virtuosamente que nos tornamos virtuosos: os atos que engendram as disposições não são de mesmo tipo que os atos que se seguem delas uma vez adquiridas. Agir por causa da virtude significa agir bem e cumprir as três condições expostas em II. 4; agir conforme à virtude significa agir bem e falhar em cumprir uma, duas ou as três condições.

\footnotetext{
${ }^{1}$ Uma primeira versão desse texto foi apresentada no I Colóquio de Filosofia Antiga UFRGS/ UFPR:Temas de Filosofia na Antiguidade, de 12 a 15 de março de 2012. Agradeço a todos os participantes do colóquio, em especial a Lucas Angioni, pelos comentários e questionamentos frutíferos. Agradeço igualmente aos pareceristas da Dois Pontos pelas sugestões e correções. Este trabalho conta com o financiamento da FAPERGS.

${ }^{2}$ Dado o objetivo prático da $E N$, a saber, de alguma forma e em alguma medida, as quais não serão aqui especificadas, tornar bons aqueles que a leem, a importância da defesa dessa tese também faz-se evidente.

${ }^{3}$ A brincadeira sobre o ‘soprar' foi usada por Gauthier e Jolif em seu comentário (GAUTHIER \& JOLIF, 1959, ad 1105a23).

${ }^{4}$ A citação a seguir, bem como toda citação feita dos textos de Aristóteles, é uma versão minha do texto grego baseadas sobretudo nas traduções de Marco Zingano (ZINGANO, 2008) e David Ross (ROSS, 1998).

5 Minha opção de tradução - na verdade, introdução do termo 'caráter', ausente no texto grego -, semelhante a de muitos tradutores, pretende ser justificada na argumentação que segue.
} 
${ }^{6}$ pros de to tas aretas eidenai ouden e mikron ischyei. Eis algumas traduções que consultei para traduzir esse trecho: Gauthier e Jolif trazem "mais pour la possession de la vertu, le savoir ne vaut que peu ou pas du tout"; Bodéüs: "mais pour la possession des vertus, justement la force du savoir est négligeable, voir nulle”; Zingano:"com relação, porém, ao possuir as virtudes, o saber pouco ou nada conta"; D. Ross: "but as a condition of the possession of the virtues knowledge has little or no weight"; H. Rackham: "but for the possession of the virtues, knowledge is of little or no avail"; Rowe: "but when it comes to having the excellences, knowledge makes no difference, or a small one"; Irwin: "As a condition for having a virtue, however, the knowing counts for nothing, or [rather] for only a little”. Agradeço a Lucas Angioni por ter chamado a minha atenção para a tradução do verbo ischyein nesse contexto.

${ }^{7}$ Zingano considera exagerada a terceira condição, caso ela seja interpretada com a introdução da palavra 'disposição': os de disposição virtuosa certamente agem virtuosamente, mas nem todo ato virtuoso, i.e., feito pelas boas razões, requer a disposição já formada do agente, bastando para tanto que ele aja bem de modo firme e não hesitante (ZINGANO, 2008, 114).

${ }^{8}$ Como bem observa Broadie, escolher o ato por ele mesmo não significa que o agente não pode visar a nada mais quando o realiza (a comentadora menciona o caso da saúde que pode ser também visada ao agirmos moderadamente, por exemplo, ao recusar comer essa comida excessivamente calórica porque ela é excessivamente calórica (BROADIE e ROWE, 2002, 300)). De fato, não penso que haja problemas em afirmar que uma ação pode ser escolhida por ser virtuosa precisamente em razão das boas consequências que trará.

\section{Referências bibliográficas}

ARISTOTELES. 1894. Ethica Nicomachea. Bywater, L. (ed.). Oxford: Clarendon Press.

BODÉÜS, R. 2004. L'Éthique à Nicomaque:Traduction inédite, présentation, notes et bibliographie. Paris: GF Flammarion.

BROADIE, S. e ROWE, C. 2002. Nicomachean Ethics. New York: Oxford University Press.

CRISP, R. 2007. Nicomachean Ethics. Cambridge: Cambridge University Press.

GAUTHIER, R-A.; JOLIF, J-Y. 1959. L’ Éthique à Nicomaque. Introduction, Traduction et Commentaire. Tome I. Louvain: Publications Universitaires de Louvain.

RACKHAM, H. 1934. Nicomachean Ethics. Loeb Classical Library (XIX). London: Harvard University Press. 
ROSS, D. 1998. Aristotle: The Nicomachean Ethics. Introduction and translation revised by J. L. Ackrill and J. O. Urmson. Oxford: Oxford University Press.

STEWART, J.A. 1892. Notes on the Nicomachean Ethics of Aristotle, v.I. Oxford: Clarendon Press.

ZINGANO. M.A. 2008. Ethica Nicomachea I 13-III 8:Tratado da virtude moral. São Paulo: Odysseus. 